\title{
Experience Affects Recruitment of New Neurons But Not Adult Neuron Number
}

\author{
Linda Wilbrecht, Alex Crionas, and Fernando Nottebohm \\ Laboratory of Animal Behavior, The Rockefeller University, New York, New York 10021
}

It is not known whether the addition of new neurons to the high vocal center (HVC) of juvenile zebra finches permits vocal learning or is the consequence of it. To tease apart these two, we performed surgery on 26 -d-old juveniles. The operations were removal of both cochleae and unilateral or bilateral denervation of the syrinx. Ability to imitate a tutor song was little affected by unilateral syringeal denervation but was severely hindered by bilateral denervation or deafening. Recruitment of new HVC neurons was studied by injecting BrdU, a cell birth marker, on post-hatching days 61-65 and killing the animals $30 \mathrm{~d}$ later. Deafening or bilateral denervation did not alter the number of BrdU-labeled neurons in HVC, but unilateral denervation nearly doubled this number in the intact side. This doubling was transient, was blocked by deafening, and was not seen in birds that received BrdU injections earlier or later in vocal ontogeny. The adult number of HVC neurons was not affected by any of our surgical procedures. Apparently experience does not affect the total number of neurons in adult HVC, but some kinds of experience can, during narrowly defined times, influence the recruitment of new HVC neurons.

Key words: song learning; neurogenesis; BrdU; unilateral denervation; sensitive period; syrinx
Many new neurons are added to the song system of birds during periods of song acquisition, both in juveniles (Alvarez-Buylla et al., 1988, 1990; Nordeen and Nordeen, 1988; Nordeen et al., 1989) and in adults (Kirn et al., 1994), suggesting that new neurons might underlie the exceptional behavioral changes that take place then. Changes in new neuron numbers in the hippocampus of birds (Barnea and Nottebohm, 1994) and mammals (Kempermann et al., 1997; Gould et al., 1999; Shors et al., 2001) have also been shown to be related to changes in experience and behavior. It is not known whether the high rate of new neuron recruitment in the song system during the sensitive period for song learning is the result of a developmental program permissive for learning or the consequence of learning taking place at the time.

We quantified new neuron recruitment in zebra finches in which we disrupted the ability to imitate song to determine whether recruitment was affected. To this end we deafened birds at post-hatching day 26. These birds were not able to hear a tutor song that they would later imitate, nor were they able to hear themselves to perfect this imitation. We also denervated the syrinx (vocal organ of birds) (see Fig. 1) bilaterally and unilaterally by cutting the tracheosyringeal (ts) nerve that controls the syringeal muscles. Because the syrinx of songbirds consists of two functionally independent halves, unilateral denervation blocked control of just one of the birds' two sound sources. In such birds, unilateral denervation is followed by full atrophy of the ipsilateral syringeal muscles (Nottebohm et al., 1979). The song system of

Received July 6, 2001; revised Nov. 2, 2001; accepted Nov. 6, 2001.

This work was supported by a National Science Foundation Graduate Research Fellowship to L.W., by Public Health Service Grant MH18343, and by generous support from Howard Phipps and the Mary Flagler Cary Charitable Trust. We thank Constance Scharff, David Vicario, and Phil Pierre for insightful discussion and comments. Special thanks for management of injections and attentive bird care to Daun Jackson, Sharon Sepe, Helen Ecklund, and Chris Moore and the staff of the Rockefeller University Field Research Center.

Correspondence should be addressed to Linda Wilbrecht, The Rockefeller University, 1230 York Avenue, Box 153, New York, NY 10021. E-mail: wilbrel@mail.rockefeller.edu.

Copyright (ㄷ) 2002 Society for Neuroscience $\quad 0270-6474 / 02 / 220825-07 \$ 15.00 / 0$ the brain also consists of two functional halves, each of which controls the ipsilateral syringeal half. As a result, it is possible to peripherally disconnect one or both halves of the song system from their respective syringeal muscles by severing one or both ts nerves. When one syringeal half is denervated, the opposite, intact side assumes responsibility for sound modulation, and when this is done early in life, the bird is still able to imitate sounds (Nottebohm et al., 1979). Thus unilateral denervation makes it possible to compare hemispheres that are or are not involved with direct syringeal control in an animal in which social variables and blood-borne factors are the same for both sides.

\section{MATERIALS AND METHODS}

Subjects and groups. All procedures affecting animals were approved by the Rockefeller Animal Care and Use Committee. We used male zebra finches (Taeniopygia guttata) of known age, hatched in our aviaries in Millbrook, NY, for all of our experiments. We labeled new neurons with the cell birth marker bromodeoxyuridine (BrdU), a thymidine analog, using injections of $100 \mu \mathrm{l}$ at a concentration of $10 \mathrm{mg} / \mathrm{ml}(\sim 0.08 \mathrm{mg} / \mathrm{gm}$ body weight); injections were given intramuscularly at 11 A.M. for 5 consecutive days.

In the first experiment, we labeled neurons born on post-hatching days 61-65 in five groups of birds (10 control, 7 unilaterally denervated, 5 bilaterally denervated, 5 deafened, 5 unilaterally denervated + deafened) and killed the animals $30 \mathrm{~d}$ after the first injection.

In a subsequent experiment, we labeled neurons during post-hatching days 61-65 (6 control, 10 unilaterally denervated birds) and killed these animals either 10 or $90 \mathrm{~d}$ after the first injection.

In a final experiment, we labeled new neurons at three other times during song ontogeny and harvested brains $30 \mathrm{~d}$ after the first injection. Series of five injections were made at post-hatch days 21-25 (four control, five unilaterally denervated), post-hatch days 35-39 (four control, six unilaterally denervated), and post-hatch days 120-124 (four control, six unilaterally denervated)

Surgery. All surgeries were performed on post-hatch day 26 using sodium pentobarbital diluted 1:5 $(0.055 \mathrm{mg} / \mathrm{gm})$ (controls were given anesthetic alone). For denervation, the tracheosyringeal branch of the hypoglossal nerve, which innervates the ipsilateral syringeal half (Paton and Manogue, 1982), the vocal organ of birds, was sectioned unilaterally or bilaterally (Fig. 1). In the unilaterally denervated birds, a balance was kept between left and right nerve cuts, to take into account that the 


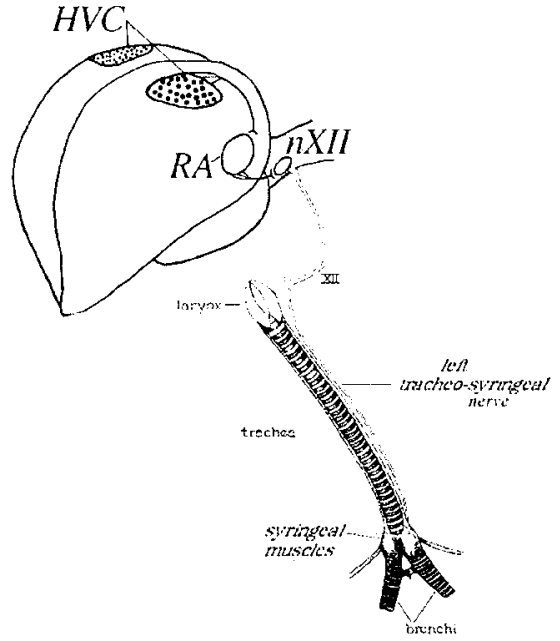

Figure 1. Schematized view of part of the male zebra finch showing the two high vocal centers $(H V C)$, and the motor output pathway of one side to nucleus robustus of the archistriatum $(R A)$, the tracheosyringeal portion of the hypoglossal nucleus ( $n X I I$ ts), and the muscles of the syrinx. Denervation involved unilateral or bilateral removal of a long segment of the ts nerve from the length of the trachea.

extent of song control exerted by both these nerves can differ in zebra finches (Williams et al., 1992). Deafening was done by removing both cochleae, as described in Konishi (1965).

Housing. All finches were kept in a standard cage $(50 \times 62 \times 38 \mathrm{~cm})$ with both of their parents and no more than one sibling after day 30 , under a photoperiod of $12 \mathrm{hr}$ light/dark, with ad libitum access to food and water. For all groups, injections, surgery, and euthanasia were performed on the correspondingly same post-hatching day. At day 65, all birds were placed singly in a smaller cage $(25 \times 46 \times 22 \mathrm{~cm})$ and then given an unrelated female companion $60-90 \mathrm{~d}$ old, to encourage singing and the normal occurrence of social relations (Zann, 1996).

Sound recording and analysis. Songs were recorded on Marantz tape recorders using Maxell $\mathrm{Cr} 02$ cassette tapes and tie-clip battery-powered microphones (Radio Shack) $3 \mathrm{~d}$ or less before perfusion. Comparisons were made with songs recorded from tutors to assess imitation using birds from all treatment groups killed at $91 \mathrm{~d}$ of age (seven control, eight unilaterally denervated, six deaf, five bilaterally denervated, five denervated and deaf). For these measurements we relied on software developed for measuring zebra finch song similarity (Tchernichovski et al., 2000). The advantage of this method is that it is quick and avoids subjective criteria that might differ between human observers. We used the software's default zebra finch settings. This setting evaluates the similarity between brief periods of sound, regardless of their temporal order, and thus is an inclusive way of screening for similarity. Because the syrinx of zebra finches can be induced to produce zebra finch-like sounds even in the absence of any innervation or learning, similarity can be found in small intervals of sound regardless of an overall failure to imitate a model. That is why two songs that, to our eye (soundspectrographic evaluation), might look very different can still get a similarity score of 30 or $40 \%$ (Fig. 2). In evaluations of song similarity and song stereotypy, we used the consistently repeated part of a song [the "motif," e.g., see Lombardino and Nottebohm (2000)] identified by eye from the visual transcription of songs.

To assess song stereotypy, a mark of maturation, in seven 91-d-old unilaterally denervated birds and seven intact controls, we compared nine motifs sung on the same day. We averaged the similarity scores obtained from the comparison of each of these motifs with the other eight.

Perfusion and histology. Birds were perfused intracardially after an overdose of diluted sodium pentobarbitol with $0.9 \%$ saline followed by $3 \%$ paraformaldehyde. Brains were removed and left in 3\% paraformaldehyde overnight. They were then washed for $24 \mathrm{hr}$ in phosphate buffer, dehydrated in alcohol over $3 \mathrm{~d}$, cleared for $1 \mathrm{hr}$ in xylene, and embedded in paraffin. Parasagittal $6 \mu \mathrm{m}$ sections were cut on a microtome and mounted on chromalum-coated glass slides.

Brains were prepared for immunohistochemistry by deparaffinization
A
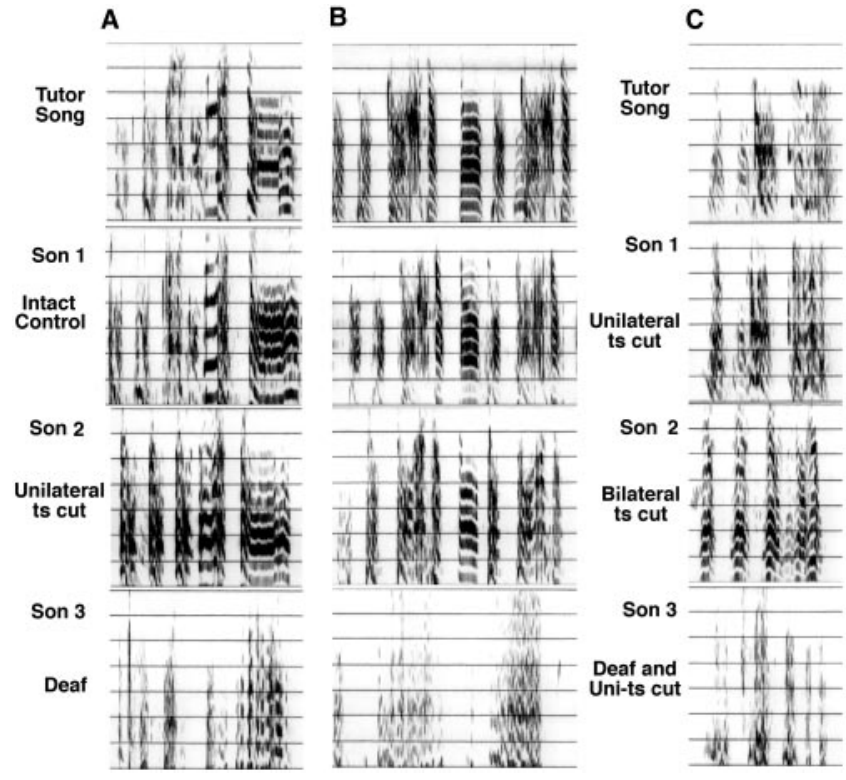

Figure 2. The songs of three tutors and their sons' imitations. For tutor $A$ and $B$, the first son shown was an intact control; the second son was unilaterally denervated, and the third was deafened. For tutor $C$, the first son shown was unilaterally denervated, the second was bilaterally denervated, and the third was unilaterally denervated and deafened. Most sons were raised apart from each other in serial clutches.

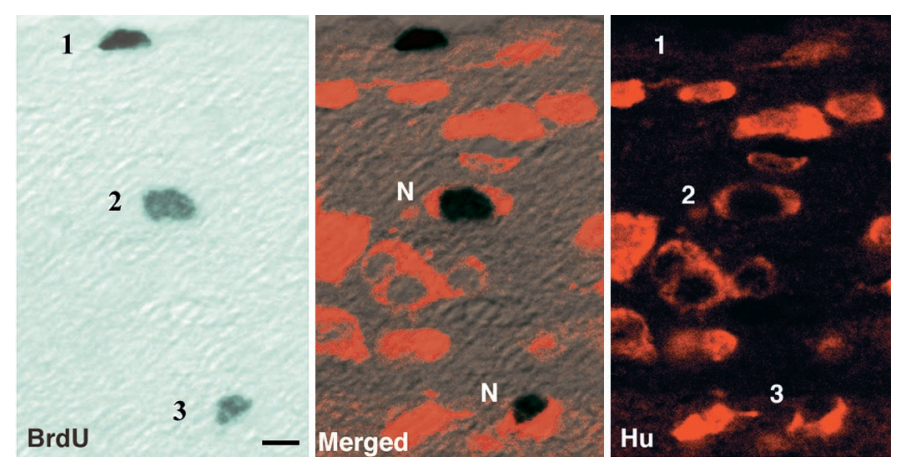

Figure 3. Left panel, BrdU+ nuclei stained with $\mathrm{DAB}$ viewed under the confocal microscope. Scale bar, $5 \mu \mathrm{m}$. Center panel, Merged images of BrdU and $\mathrm{Hu}$ showing one single labeled cell (1), not counted, and two double-labeled cells $(2,3)$ counted as new neurons $(N)$. Right panel, $\mathrm{Hu}+$ cells under the confocal microscope counted to determine total neuron number in HVC.

in xylene, denaturation in citric acid/sodium citrate buffer, and a weak pepsin incubation. After incubation in 10\% normal horse serum and $0.3 \%$ Triton X-100, a mouse monoclonal antibody against BrdU (1:200, Dako, Carpinteria, CA) and a horse biotinylated secondary antibody (1:200, Vector, Burlingame, CA) were used to first stain BrdU+ nuclei with diaminobenzidine (DAB) using an $\mathrm{ABC}$ Elite reaction kit (Vector). This staining was followed by a mouse Hu 16A11 primary (1:500, Molecular Probes, Eugene, OR) and a donkey Cy-3 (1:200, Jackson ImmunoResearch, West Grove, PA) fluorescent secondary antibody to stain the Hu protein in the cytoplasm of neurons (Barami et al., 1995). Previous DAB staining prevented any secondary cross reactivity (Valnes and Brandtzaeg, 1982). All brains were analyzed using a $63 \times$ objective on a computer-yoked microscope (Alvarez-Buylla and Vicario, 1988). The identity of each BrdU+ nucleus identified under the light microscope was checked under fluorescence for the neuronal marker $\mathrm{Hu}$. $\mathrm{BrdU}+\mathrm{DAB}$-stained nuclei with a $\mathrm{Hu}+\mathrm{Cy}-3$ halo were counted as new neurons (Fig. 3). A $1 \mathrm{~mm}^{2}$ portion of the high vocal center (HVC) was mapped for each hemisphere; this typically involved mapping five or more sections of HVC throughout the fullest parts of the nucleus. The 


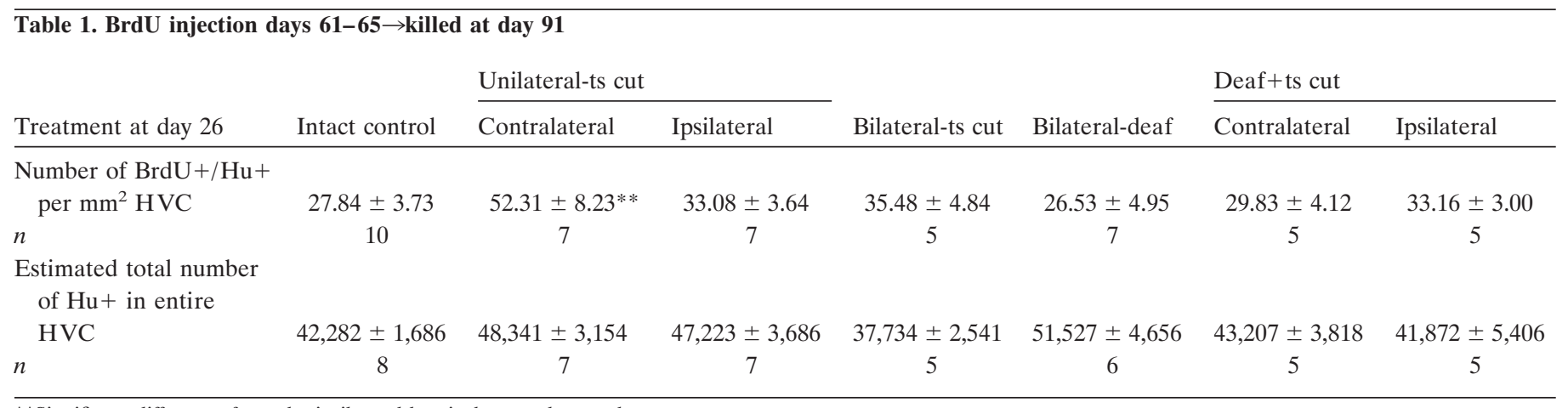

**Significant difference from the ipsilateral hemisphere and controls.

sections used were at least $60 \mu \mathrm{m}$ apart. In those cases in which birds received unilateral treatment, we analyzed both hemispheres individually. In the rest of the groups, after we determined that the right/left differences were not significant, we then used data from just the right hemisphere for comparisons.

Quantification of results. Comparisons of more than two groups were first performed using a nonparametric Kruskal Wallis one-way ANOVA. Comparisons of two groups were made using a Mann-Whitney $U$ test or Wilcoxon matched pairs signed rank test when comparing two hemispheres from the same birds. All $p$ values reported are two-tailed; $p<$ 0.05 was treated as the threshold for significance. SEM is indicated in Tables and Figures.

Estimates of the total number of $\mathrm{Hu}+$ cells (i.e., neurons) and of the total number of cells that were $\mathrm{Hu}+$ and $\mathrm{BrdU}+$ (i.e., new neurons) were made for the entire nucleus using volume estimates and the Abercrombie correction equation [number of cells per volume $=$ number of cells per area $\times(T /(T+D)]$ to accurately count sectioned objects by accounting for section thickness $(T)$ and average nuclear diameter $(D)$ (Guillery and Herrup, 1997). Estimates of HVC volume were made by measuring its area every $180 \mu \mathrm{m}$ throughout the brain. Where nucleus robustus of the archistriatum (RA) volume was assessed, it was measured every $120 \mu \mathrm{m}$. We measured the diameter of 20 nuclei that were $\mathrm{BrdU}+$ and $\mathrm{Hu}+$, and 50 nuclei of $\mathrm{Hu}+$ cells in the ipsilateral and contralateral $\mathrm{HVC}$ of five unilateral ts cut birds, and the right hemisphere of five control birds and five deaf birds, all $91 \mathrm{~d}$ old. For calculations of percentage of neurons labeled in the $1 \mathrm{~mm}^{2}$ area covered in mapping, neuron density was assessed by averaging the number of $\mathrm{Hu}+$ cells counted in three 0.012 $\mathrm{mm}^{2}$ fields of each HVC section mapped for each bird in all groups. Each field was counted, taking care to exclude cells touching two sides of the rectangular visual field, and counts were corrected when converted to volumes. Density of neurons in RA was also assessed in this manner in unilaterally denervated and control groups at $91 \mathrm{~d}$.

The above methods were used to generate three estimates: number of new neurons per square millimeter (uncorrected), total number of new HVC neurons (corrected), and percentage of HVC neurons that were BrdU labeled (uncorrected). Our comparisons between groups yielded very similar results using any of these three methods. For the sake of simplicity, we present our data as number of new neurons per square millimeter. This is justified because there were no differences between groups in neuronal density or nuclear diameter of new neurons.

Terminology. We counted numbers of BrdU+ and $\mathrm{Hu}+$ cells, and therefore presumed "new" neurons, 5-90 d after injection of the birth date marker (BrdU). The numbers seen at the shorter survival are likely to be underestimates because neurons born elsewhere may not yet have migrated to their final destination. At longer survivals, the number of neurons is likely to be influenced by selective attrition (Kirn et al., 1999). In short, we chose the term "recruitment" to refer to the number of new neurons present at any one time, without attempting to tease apart the contributions of production, migration, and survival.

\section{RESULTS}

\section{Unilateral denervation affected the recruitment of new neurons, but deafening and bilateral denervation did not}

Thirty days after BrdU injections on post-hatching day 61-65, significantly more BrdU+ neurons were recruited into the HVC

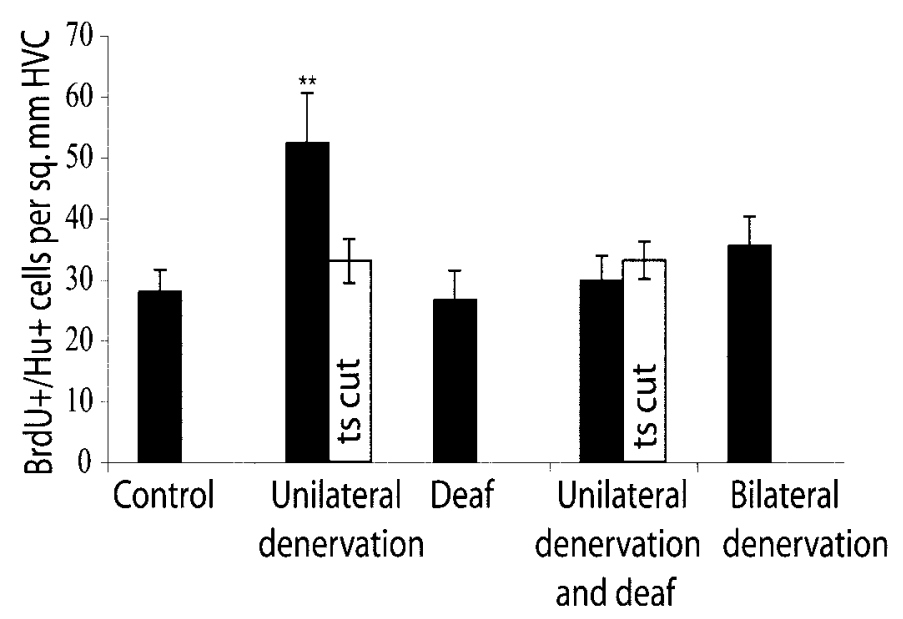

Figure 4. Bar graph comparing the number of $\mathrm{BrdU}+/ \mathrm{Hu}+$ cells per square millimeter in HVC $30 \mathrm{~d}$ after injection at days $61-65$. Unilaterally denervated birds have values for counts in HVC ipsilateral (white) and contralateral (black) to the ts nerve section. Asterisks above the bar for the contralateral $\mathrm{HVC}$ of the unilaterally denervated birds indicate a significant difference from its ipsilateral partner and control birds. When unilateral denervation is combined with deafening, the difference in new neuron number between the two HVCs is no longer seen. Error bars indicate SEM.

contralateral (contra-) to nerve section than in the ipsilateral (ipsi-) one or that of controls (1.6 times more in contra- than ipsi-, $p=0.03$, and 1.9 times more in contra- than in intact control birds, $p=0.007$ ) (Table 1, Fig. 4).

When birds were only deafened but not denervated, the number of labeled HVC neurons was not significantly different from that in age-matched intact controls $(p=0.96)$. Likewise, bilateral denervation did not change the number of $\mathrm{BrdU}+$ neurons recruited to HVC when compared with intact controls $(p=0.43)$.

No significant left/right differences were detected in the number of $\mathrm{Brdu}+/ \mathrm{Hu}+$ cells in the HVCs of the two hemispheres in control, bilaterally denervated, or deafened birds $(p>0.2$; data not shown). The volume of RA and the density of neurons within it did not differ significantly between controls $(n=7)$ and the ipsilateral or contralateral sides of unilaterally denervated birds $(n=7)$ (volume: controls $0.134 \pm 0.021 \mathrm{~mm}^{3}$, contra- $0.122 \pm 0.012$ $\mathrm{mm}^{3}$, ipsi- $0.115 \pm 0.014 \mathrm{~mm}^{3}$, control vs contra- $p=0.62$, control vs ipsi- $p=0.36$, contra- vs ipsi- $p=0.21$; density: controls $52 \pm 2$ neurons in three $63 \times$ fields, contra- $54 \pm 2$, ipsi- $48 \pm 2$, control vs contra- $p=0.58$, control vs ipsi- $p=0.39$, contra- vs ipsi- $p=0.15$ ). 
Table 2. BrdU injection days 61-65 $\rightarrow$ killed 10, 30, or $90 \mathrm{~d}$ later

\begin{tabular}{|c|c|c|c|c|c|c|c|c|c|}
\hline & \multicolumn{3}{|l|}{$61-65 \rightarrow 71$} & \multicolumn{3}{|l|}{$61-65 \rightarrow 91$} & \multicolumn{3}{|l|}{$61-65 \rightarrow 150$} \\
\hline & \multirow[b]{2}{*}{ Intact control } & \multicolumn{2}{|l|}{ Unilat-ts cut } & \multirow[b]{2}{*}{ Intact control } & \multicolumn{2}{|l|}{ Unilat-ts cut } & \multirow[b]{2}{*}{ Intact control } & \multicolumn{2}{|l|}{ Unilat-ts cut } \\
\hline & & Contralateral & Ipsilateral & & Contralateral & Ipsilateral & & Contralateral & Ipsilateral \\
\hline \multicolumn{10}{|l|}{ Number of BrdU+/ } \\
\hline $\mathrm{Hu}+$ per $\mathrm{mm}^{2} \mathrm{HVC}$ & $17.47 \pm 8.62$ & $29.76 \pm 6.66$ & $25.43 \pm 3.91$ & $27.84 \pm 3.73$ & $52.31 \pm 8.23^{* *}$ & $33.08 \pm 3.64$ & $36.51 \pm 6.26$ & $38.42 \pm 3.23$ & $41.64 \pm 1.82$ \\
\hline$n$ & 3 & 5 & 5 & 10 & 7 & 7 & 3 & 5 & 5 \\
\hline \multicolumn{10}{|l|}{$\begin{array}{l}\text { Estimated total number } \\
\text { of } \mathrm{Hu}+\text { in entire }\end{array}$} \\
\hline HVC & $37,901 \pm 4,588$ & $37,925 \pm 4,220$ & $39,183 \pm 4,063$ & $42,282 \pm 1,686$ & $48,341 \pm 3,154$ & $47,223 \pm 3,686$ & $48,436 \pm 5,204$ & $44,775 \pm 3,861$ & $43,352 \pm 2,891$ \\
\hline$n$ & 3 & 5 & 5 & 8 & 7 & 7 & 9 & 11 & 11 \\
\hline
\end{tabular}

**Significant difference from the ipsilateral hemisphere and controls.

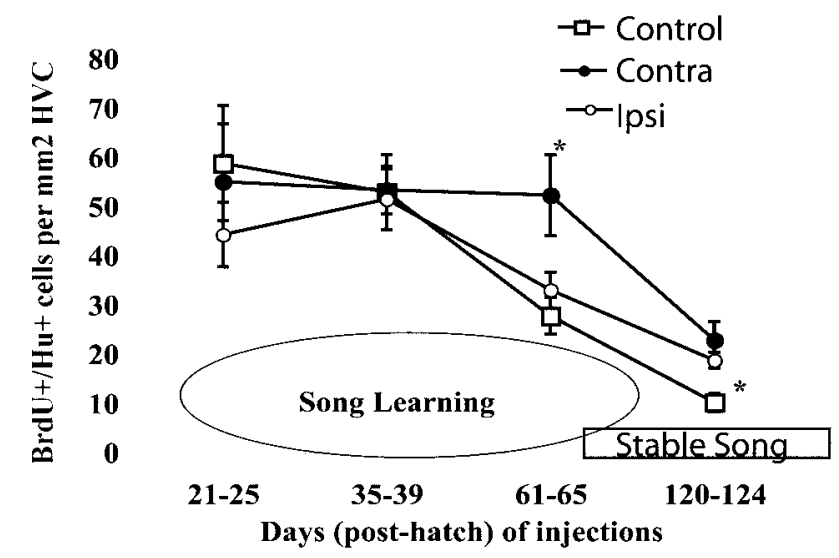

Figure 5. Decline in $\mathrm{BrdU}+/ \mathrm{Hu}+$ cells per square millimeter in $\mathrm{HVC}$ during the period for song learning. Injections were made at four different times during song learning, and birds were killed $30 \mathrm{~d}$ after the first injection. Intact controls are represented by open squares, and unilaterally denervated birds are represented by open and closed circles. Open circles correspond to counts from the HVC ipsilateral to the ts nerve cut, and closed circles indicate values from the intact side contralateral to the nerve cut. For groups injected at days 61-65 and killed at day 91, the HVC contralateral to denervation is significantly higher than the ipsilateral side and controls. For groups injected at days 120-124 and killed at day 150, the asterisk indicates that the ipsilateral side of unilaterally denervated birds is significantly higher than controls. Error bars indicate SEM.

\section{Deafening cancelled the effect of unilateral denervation on new neuron numbers}

When unilateral denervation was combined with bilateral deafening, the increased recruitment of BrdU+ neurons born between days 61 and 65 was no longer observed (Table 1, Fig. 4). In this set of birds the number of new neurons per square millimeter did not differ between the contralateral and ipsilateral sides $(p=$ 0.43 ) and was not significantly different from that in intact controls $(p=0.35)$.

\section{Birds that sustain unilateral denervation of their vocal organ can imitate a tutor's song}

Song similarity was assessed using sound analysis software (Tchernichovski et al., 2000). Songs of intact (control) birds had a similarity score of $75.9 \pm 6.6 \%$ SEM. The imitations of unilaterally denervated birds were not significantly different when compared with controls (similarity score of $62.6 \pm 5.7 \%$ SEM; $p=$ 0.12 ). In contrast, the other manipulations produced scores significantly lower than those of unilaterally denervated birds. Songs of birds that had been bilaterally denervated (similarity score $43.2 \pm 5.1 \%$ SEM; $p=0.03$ ), songs of birds that were deaf $(34.9 \pm 6.91 \%$ SEM; $p=0.01)$, and songs of birds that were deaf and unilaterally denervated $(33.8 \pm 8.8 \%$ SEM; $p=0.01)$ were grossly abnormal, bearing little resemblance to the complex features of the tutor's song (Fig. 2).

To assess whether unilateral denervation arrested song development, we compared the songs of these birds at day 91 with those of intact controls. Comparisons of motifs sung on the same day showed comparable song stereotypy in intact $(82.4 \pm 2.74 \%$ SEM) and unilaterally denervated birds $(88.1 \pm 1.66 \%$ SEM $)$, suggesting that elevated levels of neuronal incorporation during late stages of song development do not reflect behavioral immaturity.

\section{Altered levels of neuronal recruitment were transient}

After finding that new neuron numbers roughly doubled in the $\mathrm{HVC}$ contralateral to ts nerve section in birds injected with BrdU during days 61-65, we wondered whether the difference between the two HVC sides was present soon after the cells were born (5-10 d survival) and whether the difference lasted for as long as $90 \mathrm{~d}$. This might be expected if the excess of new neurons in the intact side embodied part of a permanent repository of long-term motor memory.

There was no significant difference between the number of 5- to 10 -d-old neurons in HVC on either side $(p=0.81)$. Moreover, there was no difference between these animals and their intact controls $(p=0.39)$. Interestingly, the difference between the two sides seen at $30 \mathrm{~d}$ survivals (above) was no longer present at $90 \mathrm{~d}$ survivals $(p=0.63)$, and the values for the two sides seen at $90 \mathrm{~d}$ survivals did not differ significantly from those of controls $(p=$ 0.68) (Table 2).

\section{Unilateral differences in neuronal recruitment did not occur at other times in development}

To determine whether unilateral denervation affected $\mathrm{HVC}$ neuronal recruitment earlier in song development or after song crystallization, we also counted BrdU-labeled neurons in birds that had been unilaterally denervated at day 26 and then received BrdU at different times in development. We injected BrdU on days 21-25, when birds are likely to imitate songs they hear but are only starting to produce sub-song; on days 35-39, when birds are still likely to imitate songs they hear and are singing advanced sub-song; and on days 120-124, when the adult learned song is sung in a stereotyped manner (Immelmann 1969; Price 1979; Eales, 1985; Boehner, 1990; Lombardino and Nottebohm, 2000; Tchernichovski et al., 2000) (Fig. 5). As in the first experiment, recruitment of new neurons was measured by the number of 
Table 3. Five days of BrdU injections throughout development $\rightarrow$ killed $30 \mathrm{~d}$ later

\begin{tabular}{|c|c|c|c|c|c|c|}
\hline & \multicolumn{3}{|l|}{$21-25 \rightarrow 51$} & \multicolumn{3}{|l|}{$35-39 \rightarrow 65$} \\
\hline & \multirow[b]{2}{*}{ Intact control } & \multicolumn{2}{|l|}{ Unilat-ts cut } & \multirow[b]{2}{*}{ Intact control } & \multicolumn{2}{|l|}{ Unilat-ts cut } \\
\hline & & Contralateral & Ipsilateral & & Contralateral & Ipsilateral \\
\hline $\begin{array}{c}\text { Number of BrdU+ } \\
\mathrm{Hu}+\text { per } \mathrm{mm}^{2}\end{array}$ & & & & & & \\
\hline HVC & $58.84 \pm 11.73$ & $55.08 \pm 11.68$ & $44.32 \pm 6.55$ & $52.93 \pm 7.66$ & $53.38 \pm 4.81$ & $51.51 \pm 6.19$ \\
\hline$n$ & 4 & 5 & 5 & 4 & 6 & 6 \\
\hline $\begin{array}{l}\text { Estimated total } \\
\text { number of } \mathrm{Hu}+ \\
\text { in entire } \mathrm{HVC}\end{array}$ & $28,768 \pm 1,575$ & $35,221 \pm 1,792^{*}$ & $42,100 \pm 3,546^{*}$ & $29,454 \pm 4,766$ & $45,080 \pm 2,651$ & $39,675 \pm 2,533$ \\
\hline$n$ & 4 & 5 & 5 & 4 & 5 & $\begin{array}{c}5 \\
\text { (Table continues) }\end{array}$ \\
\hline
\end{tabular}

*Significant difference from controls of the same age.

**Significant difference from the ipsilateral hemisphere and controls.
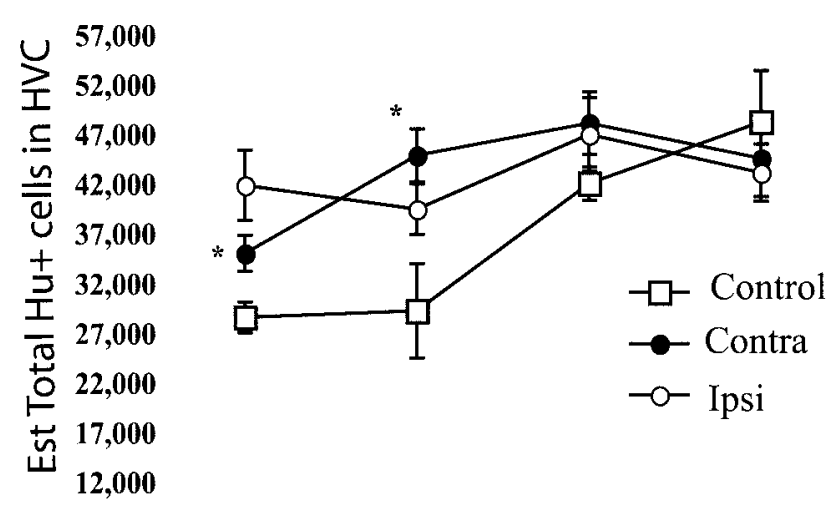

age 51

65

91

150

Figure 6. The total number of $\mathrm{Hu}+$ cells in $\mathrm{HVC}$ increases during the period for song learning. Shown are measurements from four different times during song learning. Intact controls are represented by open squares, and open circles correspond to counts from the HVC ipsilateral to the ts nerve cut; closed circles indicate values from the intact side contralateral to the nerve cut. At post-hatch day 51, the asterisk indicates that the HVC of both sides of denervated birds is significantly larger than that of controls. At day 65, the asterisk indicates that only the HVC contralateral to ts nerve cut is significantly larger than that of controls. After this period there is no significant difference between groups. Error bars indicate SEM.

$\mathrm{Hu}+/ \mathrm{BrdU}+$ neurons per square millimeter in HVC $30 \mathrm{~d}$ after the first BrdU injection.

In the youngest of these groups (days 21-25), finches added BrdU+ HVC neurons at a relatively high rate of $58.9 \pm 11.7$ neurons per square millimeter. Then progressively fewer labeled neurons were incorporated into $\mathrm{HVC}$, so that in our oldest group of birds, which had settled on their stable adult song, only $10.2 \pm$ 1.8 labeled neurons per square millimeter were found in HVC (Table 3, Fig. 5). The time course of decline in the number of labeled HVC neurons ipsilateral to the nerve section closely followed that of intact control animals. On the intact contralateral side, the number of BrdU-labeled neurons was similar to that seen in the ipsilateral side, except for the group injected with BrdU at days 61-65, which yielded a higher count, as described earlier. A significant difference in neuronal recruitment between ipsilateral and contralateral HVC sides was not evident at any other time point $(p>0.31)$. Interestingly, in unilaterally denervated adults injected with BrdU on days 121-124 and killed at day 150, the number of BrdU-labeled neurons added to HVC of both operated and unoperated sides was higher than in controls, although only the ipsilateral side was significantly different (contra- vs control, $p=0.06$; ipsi- vs control, $p=0.02$ ).

\section{Unilateral differences in neuronal recruitment are not accompanied by differences in nuclear diameter, neuronal density, or total neuron number}

The treatment groups did not vary with respect to nuclear diameter of new neurons $(\mathrm{BrdU}+/ \mathrm{Hu}+)(p=0.62)$ or neurons of unknown age $(\mathrm{Hu}+)$ at day 91 ( $p=0.40$; data not shown). We noted, in all groups, that BrdU+ neurons were significantly larger than the rest of the neurons, which has been observed before $(p=0.004)$ (Kirn et al., 1999). This was accounted for in corrections to estimate total neuron counts, using the mean attained for each treatment group (see Materials and Methods). The density of $\mathrm{Hu}+$ cells in HVC did not vary between groups at any age ( $p>0.21$; data not shown). These results allowed us to calculate total neuron numbers from measures of density and HVC volume.

The total neuron numbers of the contralateral and ipsilateral side of unilaterally denervated finches were similar at all ages sampled, even when recruitment numbers differed $(p>0.31)$. The total number of HVC neurons of birds that had been unilaterally denervated was larger at post-hatch day 51 (contra-, $p=$ 0.03 ; ipsi-, $p=0.015$ ) and post-hatch day 65 (contra-, $p=0.03$; ipsi-, $p=0.11$ ) than in age-matched intact controls (Table 3 , and Fig. 6). There was no difference in the total number of HVC neurons in controls and in any of the experimental groups at any later survival date (from day 71, $p>0.10$ ) (Tables 1-3, Fig. 6).

\section{DISCUSSION}

Several lines of work suggest that HVC adult neuron number is remarkably independent of experience. Burek et al. (1991) showed that the total number of HVC neurons in zebra finches deafened early in ontogeny was no different from that seen in intact controls. In line with this, Brenowitz et al. (1995) showed that marsh wrens (Cistothorus palustris) induced to learn large song repertoires had no more HVC neurons than those that, because of limited tutoring, had small repertoires. Our observations indicate that the number of $\mathrm{HVC}$ neurons present in adulthood is much the same in intact zebra finches that mastered a model as in those that, because of early deafness or syringeal denervation, were unable to imitate a model. Taken together, these observations would seem to close the door for a possible role of experience in recruitment of 


\begin{tabular}{|c|c|c|c|c|c|}
\hline \multicolumn{3}{|l|}{$61-65 \rightarrow 91$} & \multicolumn{3}{|l|}{$120-24 \rightarrow 150$} \\
\hline \multirow[b]{2}{*}{ Intact control } & \multicolumn{2}{|l|}{ Unilat-ts cut } & \multirow[b]{2}{*}{ Intact control } & \multicolumn{2}{|l|}{ Unilat-ts cut } \\
\hline & Contralateral & Ipsilateral & & Contralateral & Ipsilateral \\
\hline $27.84 \pm 3.73$ & $52.31 \pm 8.23^{* *}$ & $33.08 \pm 3.64$ & $10.23 \pm 1.84$ & $22.91 \pm 3.74$ & $18.83 \pm 1.63^{*}$ \\
\hline 10 & 7 & 7 & 4 & 6 & 6 \\
\hline $42,283 \pm 1,686$ & $48,341 \pm 3,154$ & $47,223 \pm 3,686$ & $48,436 \pm 5,204$ & $44,775 \pm 3,861$ & $43,352 \pm 2,891$ \\
\hline 8 & 7 & 7 & 9 & 11 & 11 \\
\hline
\end{tabular}

new HVC neurons. Yet, a subset of our observations suggests that experience plays a role in this recruitment, even if this role does not affect eventual neuron number.

Unilateral denervation of the syrinx was conceived as a way to reduce variables while still addressing issues related to learning. We reasoned that in the unilaterally denervated birds we would be able to compare neuronal recruitment in a hemisphere directly involved in syringeal control and in one that was not. We report here that unilateral denervation affects neuronal recruitment to HVC during the sensitive period for song learning and thereafter, although it does not appear to affect the total neuron number in HVC at maturity. We report, too, that this effect occurs only if the birds are able to hear themselves sing.

To review, at $51 \mathrm{~d}$ of age the total number of $\mathrm{HVC}$ neurons was significantly smaller in the intact controls than in either side of the unilaterally denervated birds, in which this number was already close to that seen in adults (Fig. 6). Yet, at $51 \mathrm{~d}$ the number of new neurons observed was the same in both groups (Fig. 5). Clearly, the dynamics of addition and replacement must have differed in the control and experimental birds before day 51, although this was not caught by our BrdU injections. Furthermore, although the number of new neurons counted was the same in birds killed at days 51 and 65 (Fig. 5), the total neuron number was increasing in younger controls but not in the denervated birds (Fig. 6). This means new neurons were likely to be added to an older population of neurons in young controls, whereas they were likely to be replacing neurons in young denervated birds with mature $\mathrm{HVC}$ volume. Differences in total neuron number disappeared after day 65 , and by day 91 the HVC of the intact controls as well as the HVC ipsilateral and contralateral to the nerve section had the same total neuron number, although recruitment of new neurons during this $30 \mathrm{~d}$ period differed. During this time, the HVC still directly involved in syringeal muscle modulation in the single nerve cut birds recruited 1.9 times more neurons than that of controls and 1.6 times more than its disconnected contralateral partner. By day 150, total HVC neuron numbers stabilized (Fig. 6 ), and yet both HVCs of the unilaterally denervated birds recruited twice as many new neurons as that of intact controls, although the absolute numbers of new neurons had decreased in all three cases (Fig. 5).

We only analyzed behavioral performance of our birds at $90 \mathrm{~d}$ of age, but birds trained with a tutor usually produce recognizable imitations of the model by days 50-60 and a very close approximation by days 80-90 (Immelmann, 1969; Zann, 1996). Arguably, the fastest occurring changes take place soon after first exposure to a tutor (Tchernichovski et al., 2001). In our case, by day 90 the unilaterally denervated birds produced copies of the song of their tutor (father) that, by our measure, were about as accurate as those of intact controls and with comparable stereotypy.

Given these observations, three questions come to mind. (1) Why was the effect of experience on neuronal recruitment obvious only in the unilaterally denervated animals? (2) Why is the effect on recruitment present only late in song acquisition and into adulthood? (3) Do our observations suggest a role of new neurons in learning?

Starting with the first question, three very different kinds of answers come to mind. (1) Increased recruitment on the intact side could result from the additional complexity of imitating a whole song with only half a syrinx. (2) Denervation of one side may provide abnormal feedback to the other one, forcing a deviation from the normal modus operandi, and this may affect the recruitment and replacement of HVC neurons. (3) The single nerve cut may also result in an attentional asymmetry, in that only the intact side can guide imitation. Because the asymmetric effect of denervation on new neurons disappeared if the bird was also deafened, some aspect of song imitation, perhaps the guidance of motor output by auditory feedback, is involved in the differences in recruitment between sides.

In terms of actual mechanisms, differences between the denervated and intact sides could result from differences in electrical activity, modulatory transmitters, or growth factors that could affect new neuron recruitment (Li et al., 2000). Because RA volume and neuron density did not differ between the intact and denervated sides, it seems unlikely that asymmetries in neuronal recruitment resulted from differences in the innervation target space of the HVC.

The second question is about the timing of the effect on new neuron recruitment. The increase in new recruitment found in unilaterally denervated birds occurred late in song learning, when song becomes increasingly stereotyped. We expected that if unilateral denervation affected neuronal recruitment, its consequences would also be evident in our youngest groups of animals, in whom the highest availability of new neurons coincided with the bird's earliest attempts to match a model and the corresponding marked changes in vocal output. Yet, this was not so. It is possible that the achievement of stereotypy makes different demands on HVC circuitry than the process that occurs when song motor skills are first developed (Pytte and Suthers, 1999). The neural events leading to song crystallization may be more sensitive to information quantity and sensory feedback than is the case 
when circuits are being built, when perhaps an intrinsic ontogenetic program has precedence over experience. In adult canaries, peaks in new neuron recruitment occur slightly later than peaks in new syllable recruitment and probably correspond more to the time when syllables become more stable, rather than when they first appear (Kirn et al., 1994). To achieve stereotypy, HVC may have to shed "incorrect" neurons and replace them by others that fortify the "correct" circuitry that survives. The idea is that a greater number of neurons doing the same thing brings stability (stereotypy) to a program's performance. If so, then the story starts with culling, and we get a readout of differences in culling activity by looking at the survival of replacement neurons; in other words, the dead explain the living.

The third question is related to the previous two: do our observations suggest a role of new neurons in learning? Our data and those from others strongly suggest that there is a program for producing an adult $\mathrm{HVC}$ that occurs even in the absence of vocal learning. This would explain why we see no difference in neuronal recruitment after deafening, bilateral denervation, or on the operated side after unilateral denervation. The total number of neurons in HVC might be determined by a ratio of new neurons to a fixed population of older neurons (Scharff et al., 2000). This fixed population could be, in HVC, the Area X-projecting neurons, which are formed mostly before the bird hatches (AlvarezBuylla et al., 1988) and are found in clusters with other HVC neurons (Kirn et al., 1999). We suggest that in the absence of learning (e.g., in the deaf or bilaterally denervated birds), neurons are culled and replaced in a stochastic manner. In contrast, as normal birds learn their song, the neuron culling and replacement may be more selective, based on use by the circuitry that produces the learned sounds.

To see the effect we describe, we had to create an asymmetry. Does the outcome reveal something about the forces that normally govern the recruitment of neurons during ontogeny and in adulthood, or have we created a phenomenon more akin to a pathology than to the normal workings of the brain? After section of one tracheosyringeal nerve, the syringeal muscles on that side atrophied. Yet, asymmetry in neuronal recruitment occurred only if the animal could hear. This suggests that differences in neuronal recruitment reflect the active process of song imitation and not simple pathology caused by muscle atrophy on one side. If precedent serves, pathologies result from the basic properties of systems, rather than being induced by these properties de novo. Our observations suggest that a degree of flexibility in the culling and replacement of neurons in an intact part of the brain can be brought about by a lesion elsewhere in the brain. In time, this kind of response could be instructive as a vehicle to reinstate lost functions after brain injury.

It is clear that an experience-independent adult neuron number can emerge from an experience-dependent recruitment process. We suggest that in future studies much more attention will have to be paid to the mechanisms that determine which of the many neurons produced during ontogeny and in adulthood survive and for how long. This more detailed approach will be necessary to determine how the culling and incorporation of new neurons are related to the acquisition and maintenance of learned skills. It is clear that data on total numbers alone miss much of the story.

\section{REFERENCES}

Alvarez-Buylla A, Vicario D (1988) A simple microcomputer system for mapping tissue section with the light microscope. J Neurosci Methods 25:165-173.

Alvarez-Buylla A, Theleen M, Nottebohm F (1988) Birth of projection neurons in the high vocal center of the canary forebrain before, during and after song learning. Proc Natl Acad Sci USA 85:8722-8726.

Alvarez-Buylla A, Kirn JR, Nottebohm F (1990) Birth of projection neurons in adult avian brain may be related to perceptual or motor learning. Science 249:1444-1446.

Barami K, Iversen K, Furneaux H, Goldman SA (1995) Hu protein as an early marker of neuronal phenotypic differentiation by subependymal zone cells of the adult songbird forebrain. J Neurobiol 28:82-101.

Barnea A, Nottebohm F (1994) Seasonal recruitment of hippocampal neurons in adult free-ranging black-capped chickadees. Proc Natl Acad Sci USA 91(23):11217-11221.

Brenowitz EA, Lent K, Kroodsma DE (1995) Brain space for learned song in birds develops independently of song learning. J Neurosci 15:6281-6286.

Boehner J (1990) Early Acquisition of song in the zebra finch, Taeniopygia guttata. Anim Behav 39:369-374.

Burek MJ, Nordeen KW, Nordeen EJ (1991) Neuron loss and addition in developing zebra finch song nuclei are independent of auditory experience during song learning. J Neurobiol 22:215-223.

Eales LA (1985) Song learning in zebra finches: some effects of song model availability on what is learnt and when. Anim Behav 33:1293-1300.

Gould E, Tanapat P, Hastings NB, Shors TJ (1999) Learning enhances adult neurogenesis in the hippocampal formation. Nat Neurosci 2:260-265.

Guillery RW, Herrup K (1997) Quantification without pontification. J Comp Neurol 386:2-7.

Immelmann K (1969) Song development in the zebra finch and other estrilid finches. In: Bird vocalizations (Hinde RA, ed), pp 64-74 Cambridge, UK: Cambridge UP.

Kempermann G, Kuhn HG, Gage FH (1997) More hippocampal neurons in adult mice living in an enriched environment. Nature 386:493-495.

Kirn J, O’Loughlin B, Kasparian S, Nottebohm F (1994) Cell death and neuronal recruitment in the high vocal center of adult male canaries are temporally related to changes in song. Proc Natl Acad Sci USA 19:7844-7848.

Kirn JR, Fishman Y, Sasportas K, Alvarez-Buylla A, Nottebohm F (1999) Fate of new neurons in adult canary high vocal center during the first 30 days after their formation. J Comp Neurol 411:487-494.

Konishi M (1965) Effects of deafening on song development in American robins and black-headed grosbeaks. Z Tierpsychol 5:584-599.

Li XC, Jarvis ED, Alvarez-Borda B, Lim DA, Nottebohm F (2000) A relationship between behavior, neurotrophin expression, and new neuron survival. Proc Natl Acad Sci USA 97:8584-8589.

Lombardino AJ, Nottebohm F (2000) Age at deafening affects the stability of learned song in adult male zebra finches. J Neurosci 20:5054-5064.

Nordeen KW, Nordeen EJ (1988) Projection neurons within a vocal motor pathway are born during song learning in zebra finches. Nature 334:149-151.

Nordeen KW, Marler P, Nordeen EJ (1989) Addition of song-related neurons in swamp sparrows coincides with memorization, not production, of learned songs. J Neurobiol 20:651-661.

Nottebohm F, Manning E, Nottebohm ME (1979) Reversal of hypoglossal dominance in canaries following syringeal denervation. J Comp Physiol [A] 134:227-240.

Paton JA, Manogue K (1982) Bilateral interactions within the vocal control pathway of birds. Two contrasting strategies. J Comp Neurol 212:329-335.

Pytte CL, Suthers RA (1999) Sensitive period for sensorimotor integration during vocal motor learning. J Neurobiol 42:172-189.

Price PH (1979) Developmental determinants of structure in zebra finch song. J Comp Physiol Psychol 93:268-277.

Scharff C, Kirn J, Macklis J, Nottebohm F (2000) Targeted neuronal death affects neuronal replacement and vocal behavior in adult songbirds. Neuron 25:481-492.

Shors TJ, Miesegaes G, Beyllin A, Zhao M, Rydel T, Gould E (2001) Neurogenesis in the adult is critically involved in the formation of trace memories. Nature 410:372-376.

Tchernichovski O, Nottebohm F, Ho CE, Pesaran B, Mitra PP (2000) A procedure for an automated measurement of song similarity. Anim Behav 59:1167-1176.

Tchernichovski O, Mitra PP, Lints T, Nottebohm F (2001) Dynamics of the vocal imitation process: how a zebra finch learns its song. Science 291:2564-2569.

Valnes K, Brandtzaeg P (1982) Comparison of paired immunofluorescence and paired immunoenzyme staining methods based on primary antisera from the same species. J Histochem Cytochem 30:518-524.

Williams H, Crane LA, Hale TK, Esposito MA, Nottebohm F (1992) Right side dominance for song control in the zebra finch. J Neurobiol 23:1006-1020.

Zann RE (1996) The zebra finch: synthesis of field and laboratory studies. Oxford, UK: Oxford UP. 